\title{
Microbiological Pattern and Antibiotic Sensitivity of Infected Chronic Foot Ulcer among the Diabetic Patients in BIRDEM Hospital
}

\author{
Tapash Kumar Maitra ', Mahmud Ekramullah ', Md. Golam Rahman ${ }^{2}$, Faruquzzaman ${ }^{2}$, Samar Chandra Saha ${ }^{3}$
}

\begin{abstract}
:
Background: Foot infections are one of the major complications of diabetes mellitus and are significant risk factors for lower extremity amputation. Providing effective antimicrobial therapy is an important component in treating these infections, which requires information about pattern of bacterial growth and their antibiotic susceptibility. This study was designed to investigate the microbial pattern of diabetic foot infections and their antibiotic susceptibility.

Methodology: This prospective study was conducted in Surgery Unit 1 of Bangladesh Institute of Research and Development in Endocrine \& Metabolism (BIRDEM) General Hospital, Dhaka, Bangladesh from September, 2013 to November 2016. A total 81 diabetic patients of infected chronic foot ulcer were selected on the basis of convenient sampling. Data were collected on demographic characteristics (age and sex), examination findings, bacterial involvement, its type and sensitivity pattern. Wagner's ulcer grading system was used to classify the chronic foot ulcers

Result: The age distribution of the sampled population depicted that over half [42(51.8\%) out 81 ] of the patients was in their $5^{\text {th }}$ decade of life. Females were slightly higher $(53.1 \%)$ than the males $(46.9 \%)$ with mean ages of the male and female patients being $48.0 \pm 1.5$ and $53.0 \pm 1.2$ respectively. Based on Wagner ulcer grading system, $45.7 \%$ of the foot ulcers were grade II followed by $21.0 \%$ grade III, $13.6 \%$ grade IV, another $13.6 \%$ grade I and only $6.2 \%$ grade 0 . Most of the infections were polymicrobial $(88.9 \%)$ and isolated micro-organisms were frequently E. coli $(47.1 \%)$ and Klebsiella (33.3\%). The antibiotics sensitivity against the micro-organisms demonstrated that colostin was the most sensitive antibiotics ( $97.5 \%$ of all cases), followed by imipenem (90.1\%) and meropenem (90.1\%).

Conclusion: Chronic foot ulcers in diabetic patients are usually associated with polymicrobial infection. E. coli, Klebsiella and Pseudomonas are the most common micro-organisms isolated, which are sensitive to colostin, imipenem and meropenem in majority of the cases.

Keywords: Microbiological pattern, antibiotic sensitivity, diabetic foot, infection.
\end{abstract}

\section{Introduction:}

Diabetes is a major cause of morbidity and mortality worldwide, costing an estimated \$245 billion in 2012 in the United States alone due to increased use of health resources and lost productivity. ${ }^{1}$ Studies have shown that the prevalences of diagnosed diabetes, ${ }^{2,3}$ total diabetes (diagnosed plus undiagnosed) ) $^{2,4}$ and type 1 diabetes $^{5}$ have increased during the past decades. ${ }^{3}$ The prevalence of diabetes is also on a rising trend in developing countries including Bangladesh. In a recent scoping review of

\section{Authors' information:}

${ }^{2}$ Dr. Tapash Kumar Maitra, Associate Professor \& Head of the Department of Surgery, BIRDEM General Hospital, Bangladesh.

${ }^{1}$ Dr. Mahmud Ekramullah, Assistant Professor, Department of Surgery, BIRDEM General Hospital, Bangladesh.

2 Dr. Md. Golam Rahman, Associate Professor, Current Charge, Department of Surgery, Rangpur Medical College, Rangpur Bangladesh.

2 Dr. Faruquzzaman, MBBS, BIRDEM General Hospital, Dhaka, Bangladesh.

${ }^{3}$ Dr. Samar Chandra Saha, Registrar, Department of Anaesthesiology, Holy Family Red Crescent Medical College Hospital Dhaka, Bangladesh

Corresponding author: Dr. Tapash Kumar Maitra, Phone: +8801817029462 Email: tapashkm1965@gmail.com 
published literatures (22 studies), where 51,252 participants were included, the prevalence of diabetes in Bangladesh was revealed to be $7.4 \%$. Although this life-threatening disease can be controlled, it is often accompanied by serious complications, and still today there is no cure. It is estimated that approximately $15-25 \%$ of people with diabetes develop a foot ulcer at some time during their lives, and $85 \%$ of major leg amputations are the result of a foot ulcer. ${ }^{6}$ The organisms implicated in foot infections are generally Staphylococcus aureus \& Streptococcus pyogens arising from the patients' own skin and Enterococci from bowel. Among the Gram positive aerobes Staphyloccoci are more prevalent. Many of these microorganisms are developing resistance to commonly used antibiotics largely due to their indiscriminate use. ${ }^{7}$

The World Health Organization (WHO) reported increasing incidence of diabetes all around the world, especially in developing countries. ${ }^{8-11}$ Neuropathy, peripheral arterial disease, and pressure overload make the sufferers prone to ulcer. People with diabetes can progress into chronic ulcers often leading to amputation if not treated promptly. ${ }^{10-13}$ Poorly controlled diabetes is prone to skin infections because elevated blood sugar reduces the effectiveness of bacteria fighting cells. Carbuncles, boils, and other skin infections may be hazardous if not properly treated. Even a small cut may progress to a deep, open sore, called an ulcer. ${ }^{14}$ Advanced age, male gender, and neglected diabetes are the other factors associated with amputation. ${ }^{10,15}$

Chronic wounds can be colonized on the surface by a wide range of organisms. ${ }^{16}$ Several studies have shown different bacterial agents isolated from diabetic foot ulcers in different geographical areas. ${ }^{9,16,17}$ The inconsistency in reports might be attributed to the varying methods of dressing and populations. If bacterial infection is mild, it is usually monobacterial and if severe infection is present, it is polymicrobial. ${ }^{18}$ The antibiotic susceptibility patterns also show variations with geographical regions. ${ }^{19,20}$ Multidrug resistant (MDR) bacteria, methicillin resistant S. aureus
(MRSA), and extended-spectrum ß-lactamase (ESBL) producing Gram-negative bacteria and their associated complications have created a big health concern among the medical and clinical practitioners. ${ }^{21,22}$ In recent decades, high rates of MDR bacteria, MRSA, and ESBL positive strains have been observed in many hospitalized diabetic foot patients (DFP). ${ }^{13,23,24}$ Such conditions make the treatment more demanding to save patients' lives.

Early diagnosis of diabetic foot ulcers and prompt initiation of appropriate antimicrobial therapy are the mainstay for controlling infection, preventing complication and improving quality of life of the patients. Antibiotic susceptibility test is essential for the management of infections which can help make better therapeutic choices. Hence, this study was designed to evaluate the presence and types of microorganisms in infected diabetic foot cases and their sensitivity patterns.

\section{Patients \& Methods:}

This cross-sectional study was carried out in Surgery Unit 1 of Bangladesh Institute of Research and Development in Endocrine \& Metabolism (BIRDEM) General Hospital, Dhaka, Bangladesh between September, 2013 to November, 2016 based on convenient sampling. Informed consent was taken from each of the participating patients after assuring them that the confidentiality and anonymity of the study subjects would be maintained rigorously. A total of 81 adult diabetic patients with infected choric foot ulcer were consecutively included in the study. However, critically-ill patients with septicaemia, were excluded from the study. Data were collected using a semi-structured questionnaire designed to include demographic information (age and sex), examination findings, bacterial involvement, its type and sensitivity pattern. Data were processed using SPSS (Statistical Packages for Social Sciences), version 17 and the test statistics used to analyse the data were descriptive statistics. Wagner's ulcer grading system ${ }^{25}$ was used as an assessment tool to classify the chronic foot ulcers as follows (Table I): 


\begin{tabular}{|l|l|}
\hline TABLE I. Wagner's ulcer grading system \\
\hline Grade & Lesion \\
\hline 0 & No open lesions; may have deformity or cellulitis. \\
\hline I & Superficial diabetic ulcer (partial or full thickness). \\
\hline II A & $\begin{array}{l}\text { Ulcer extension to ligament, tendon, joint capsule, or } \\
\text { deep fascia without abscess or osteomyelitis. }\end{array}$ \\
\hline II B & Deep ulcer with abscess, osteomyelitis, or joint sepsis. \\
\hline III & Gangrene localized to portion of forefoot or heel. \\
\hline IV & Extensive gangrenous involvement of the entire foot. \\
\hline
\end{tabular}

\section{Results:}

The age and sex distribution of the sampled population is depicted in Table II. Over half [51.9\% (42 out 81 ] of the patients was in their 5 th decade of life. Females were slightly higher $(53.1 \%)$ than the males $(46.9 \%)$ with mean ages of the male and female patients being $48.0 \pm 1.5$ and $53.0 \pm 1.2$ respectively. Wagner grading system of foot ulcer showed that about $46 \%$ had grade II ulcer followed by $21 \%$ grade III, $13.6 \%$ grade IV and another $13.6 \%$ grade I (Figure 1 ).

Microbiological study revealed that most the infections was polymicrobial (88.9\%) (Figure 2) and Escherichia coli was the predominant micro-organism ( $47.1 \%)$ isolated on culture of pus or wound swab obtained from the infected lesion followed by Klebsiella (33.3\%), Pseudomonas $(28.4 \%)$, Staphylococcus (25.9\%), Enterococcus $(21 \%)$ and Streptococcus (16\%) (Figure 3).

Sensitivity of the micro-organisms to antibiotics is shown in Table III. Most of the microorganisms were susceptible to colostin $(97.5 \%)$, imipenem $(90.1 \%)$, meropenem (90.1\%) and amikacin $(82.7 \%)$. The second line sensitive antibiotics were cefepime $(65.4 \%)$ and piperacillin and tazobactam (63\%).

TABLE II. Age and sex distribution of study subjects $(\mathbf{n}=\mathbf{8 1})$

\begin{tabular}{|c|c|c|c|c|}
\hline Age (years & $\begin{array}{r}M \\
\text { Frequency }\end{array}$ & $\begin{array}{l}\text { ale } \\
\text { Percentage }\end{array}$ & $\begin{array}{r}\text { Fen } \\
\text { Frequency }\end{array}$ & $\begin{array}{l}\text { nale } \\
\text { Percentage }\end{array}$ \\
\hline $31-40$ & 02 & 2.5 & 00 & 00 \\
\hline $41-50$ & 09 & 11.1 & 09 & 11.1 \\
\hline $51-60$ & 19 & 23.5 & 23 & 28.4 \\
\hline$>60$ & 08 & 9.9 & 11 & 13.6 \\
\hline Total & 38 & 46.9 & 43 & 53.1 \\
\hline Mean \pm SD & \multicolumn{2}{|c|}{$48 \pm 1.5$} & \multicolumn{2}{|c|}{$53 \pm 1.2$} \\
\hline
\end{tabular}

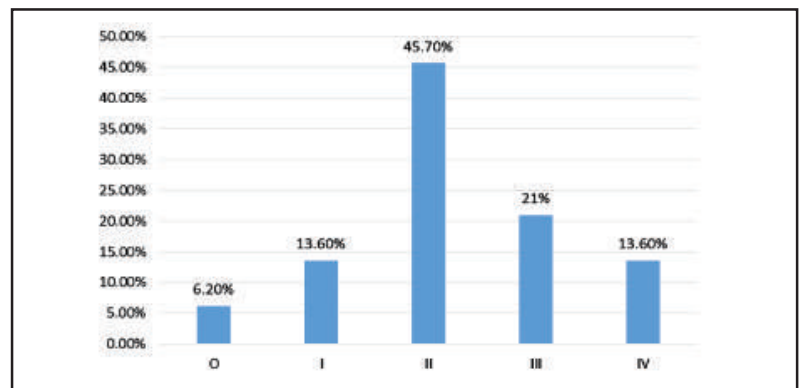

Figure 1: Grading of foot ulcer by Wagner grading of system

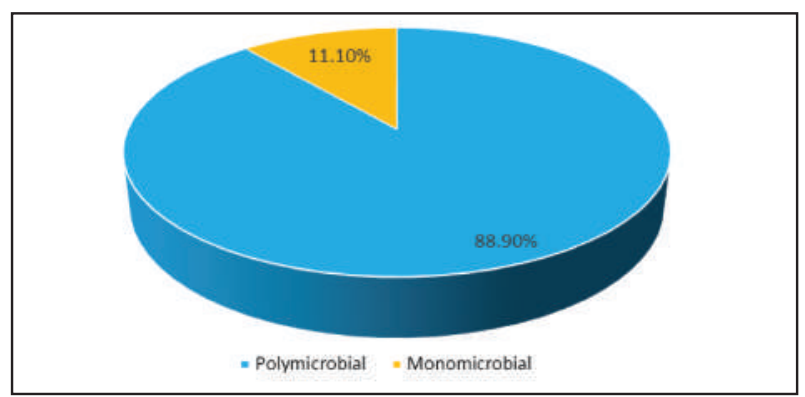

Figure 2: Microbiological pattern of foot infection.

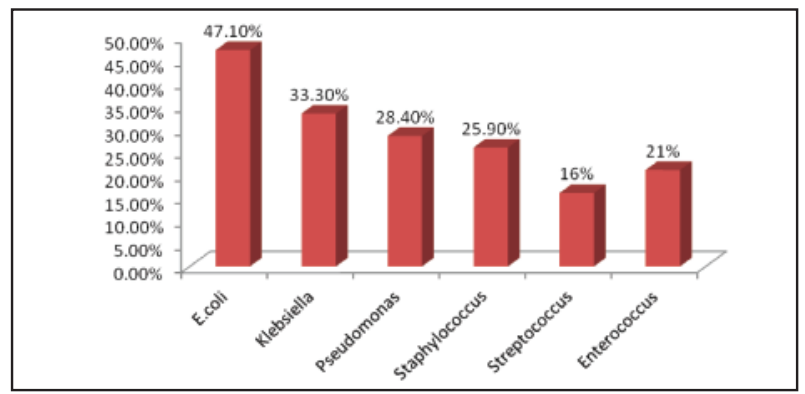

Figure 3: Isolation of micro-organisms in culture.

TABLE III. Distribution isolated bacteria by their sensitivity to antibiotics $(\mathbf{n}=\mathbf{8 1})$

$\begin{array}{lcc}\text { Sensitive antibiotics } & \text { Frequency } & \text { Percentage } \\ \text { Colistin } & 79 & 97.5 \\ \text { Imipenem } & 73 & 90.1 \\ \text { Meropenem } & 73 & 90.1 \\ \text { Amikacin } & 67 & 82.7 \\ \text { Cefepime } & 53 & 65.4 \\ \text { Piperacillin tazobactam } & 51 & 63.0 \\ \text { Gentamicin } & 47 & 58.0 \\ \text { Ceftazidime } & 41 & 50.6 \\ \text { Ceftriaxone } & 30 & 38.3 \\ \text { Amoxicillin clavulanic acid } & 29 & 35.8 \\ \text { Tobramycin } & 27 & 33.3 \\ \text { Cefalexin } & 21 & 25.9 \\ \text { Cefotaxime } & 19 & 23.4 \\ \text { Ciprofloxacin } & 18 & 22.2 \\ \text { Trimethoprim-sulfamethoxazole } & 17 & 21.0 \\ \text { Chloramphenicol } & 14 & 17.3 \\ \text { Ampicillin } & 11 & 13.6 \\ \text { Tetracycline } & 11 & 13.6\end{array}$




\section{Discussion:}

This prospective study was conducted with a total of 81 diabetic patients with infected chronic foot. Females were a bit higher $(53.1 \%)$ than the males (46.9\%). Among the male population $23.5 \%$ were in 51 - 60 years age group, whereas among females $28.4 \%$ were in their $5^{\text {th }}$ decade of life. The mean ages of the male and female patients were $48 \pm 1.5$ years and $53 \pm 1.2$ years respectively. In another clinical study, majority was male $55.9 \%$ and most of them were in 51 to 70 years of age group. ${ }^{4}$ By using the Wagner ulcer grading system, 20 about $46 \%$ of the foot ulcers were graded as grade II followed by $21 \%$ as grade III and $13.6 \%$ as grade IV which in another study was $17 \%, 36 \%$ and $16 \%$ respectively. ${ }^{24}$ In our study, $88.9 \%$ of all infections was polymicrobial which compares well with a previously cited similar study (81.9\%). ${ }^{25}$ Most frequently observed micro-organisms in this study were $E$. coli (47.1\%) and Klebsiella (33.3\%) which together comprised $80 \%$ of the microorganisms. Anvarinejad and associates in a similar study showed Enterococcus (27.0\%) and Staphylococcus $(22.0 \%)$ to be the main organisms isolated, 24 while Kiadaliri et $\mathrm{al}^{7}$ reported Staphylococcus to be the predominant (42.3\%) followed by Pseudomonas (24.3\%). In another study, it was found that over $90 \%$ of all infections in diabetic foot ulcer was associated with polymicrobial infection and the most frequent organism was Staphylococcus aureus (37.1\%) and E. coli $(22.9 \%){ }^{26}$ Sharply contrasting with these findings, a study reported that over $40 \%$ of the infections were associated with Streptococcus and Staphylococcus. ${ }^{27}$

Antibiotic sensitivity pattern in our study demonstrated that colostin was the most sensitive antibiotics $(97.5 \%)$, followed by Imipenem (90.1\%) and meropenem (90.1\%). Similar results were observed in another study, where polymyxin $B$ and colistin were found $100 \%$ sensitive. ${ }^{24}$ In a prospective study, it was found that all the Gram negative isolates were susceptible to carbapenem and beta lactum antibiotic imipenem, which is resistant to inactivation by most bacterial beta lactamases. And so it has the widest spectrum of antibacterial activity. ${ }^{8}$

In a clinical study, it was found that most of the infections were susceptible to imipenem and meropenem, where colostin sensitivity was not measured. ${ }^{26}$ In another study, the sensitivities of meropenem, colstin and imipenem were $96.6 \%$, $94.8 \%$ and $90 \%$ respectively. ${ }^{27}$ In our study, the sensitivities of aminoglycosides like amikacin and gentamycin were 82.2 and $58.0 \%$ respectively. Similar pattern was observed in most of the studies with a few exceptions. ${ }^{27-31}$

\section{Conclusion:}

Most of the chronic infected foot ulcers in diabetic patients are polymicrobial and E. coli, Klebsiella and Pseudomonas are commonly isolated micro-organisms. The microorganisms isolated were mostly sensitive to colistin, imipenem and meropenem.

\section{Reference:}

1. American Diabetes Association, Yang W, Dall TM, Halder P, Gallo P, Kowal SL et al. Economic costs of diabetes in the U.S. in 2012. Diabetes Care 2013;36(4):1033-46.

2. Cowie CC, Rust KF, Ford ES, Eberhardt MS, Byrd-Holt DD, Li C et al. Full accounting of diabetes and pre-diabetes in the US population in 1988-1994 and 2005-2006. Diabetes Care 2009;32(2):287-94.

3. Geiss LS, Wang J, Cheng YJ, Thompson TJ, Barker L, Li $Y$, Albright AL et al. Prevalence and incidence trends for diagnosed diabetes among adults aged 20 to 79 years, United States, 1980-2012. JAMA 2014;312(12):1218-26.

4. Selvin E, Parrinello CM, Sacks DB \& Coresh J. Trends in prevalence and control of diabetes in the United States, 1988-1994 and 1999-2010. Ann Intern Med 2014;160(8):517-25.

5. Menke A, Orchard TJ, Imperatore G, Bullard KM, Mayer-Davis E \& Cowie CC. The prevalence of type 1 diabetes in the United States. Epidemiology 2013; 24(5):773-74.

6. Ramani A, Ramani R, Shivananda PG \& Kundaje GN. Bateriology of diabetic foot ulcers. Indian $J$ pathol Micronbiol 1991,34:81-87.

7. Kiadaliri AA, Najafi B \& Mirmalek SM. Quality of life in people with diabetes: a systematic review of studies in Iran. Journal of Diabetes and Metabolic Disorders 2013;12(1):54. 
8. Hadadi A, Omdeh GH, Hajabdolbaghi M, Zandekarimi M \& Hamidian R. Diabetic Foot: infections and outcomes in Iranian admitted patients. Jundishapur Journal of Microbiology 2014;7(7):77-79.

9. Larijani B \& Ranjbar SH. Overview of diabetic foot; novel treatments in diabetic foot ulcer. DARU 2008; (16):1-6.

10. Won SH, Chung CY, Park MS, Lee T, Sung KH, Lee SY et al. Risk factors associated with amputation-free survival in patient with diabetic footulcers. Yonsei Medical Journal 2014;55(5):1373-78.

11. Haji ZN, Burns J, Vicaretti M, Fletcher JP, Begg L \& Hitos $\mathrm{K}$. Characteristics of diabetic foot ulcers in Western Sydney, Australia. Journal of Foot and Ankle Research 2014;7(1):39-41.

12. Gadepalli R, Dhawan B, Sreenivas V, Kapil A, Ammini, AC \& Chaudhry R. A clinico-microbiological study of diabetic foot ulcers in an Indian tertiary care hospital. Diabetes Care 2006;29(8):1727-32.

13. Deribe B, Woldemichael K \& Nemera G. Prevalence and factors influencing diabetic foot ulcer among diabetic patients attending arbaminch hospital. south ethiopia Research 2014;2(2):56-66.

14. Vimalin H \& Lali G. Studies on bacterial infections of diabetic foot ulcer. African Journal of Clinical and Experimental Microbiology 2010;11(3):146-50.

15. Matsuura GT \& Barg N. Update on the antimicrobial management of foot infections in patients with diabetes. Clinical Diabetes 2013;31(2):59-65.

16. Akhi MT, Ghotaslou R, Asgharzadeh M, Varshochi M, Pirzadeh T, Memar MY et al. Bacterial etiology and antibiotic susceptibility pattern of diabetic foot infections in Tabriz, Iran. GMS Hygiene and Infection Control 2015;10(3):71-75.

17. Dezfulian A, Salehian M, Amini V, H Dabiri, M Azimi Rad, M M Aslani et al. Bacteriological study of diabetic foot infections in an Iranian hospital. Iranian Red Crescent Medical Journal 2011;13(8):590-91.

18. Mathangi $T$ \& Prabhakaran P. Prevalence of bacteria isolated from type 2 diabetic foot ulcers and the antibiotic susceptibility pattern. International Journal of Current Microbiology and Applied Sciences 2013; (10):329-37.

19. Turhan V, Mutluoglu M, Acar A, Önem Y, Uzun G, Ay H et al., Increasing incidence of Gram-negative organisms in bacterial agents isolated from diabetic foot ulcers. The Journal of Infection in Developing Countries 2013;7(10):707-12.

20. Amini M, Davati A \& Piri M. Determination of the resistance pattern of prevalent aerobic bacterial infections of diabetic foot ulcer. Iranian Journal of Pathology 2013;8(1):21-26.
21. Farshad S, Anvarinejad M, Tavana AM \& Abdolvahab A. Molecular epidemiology of Escherichia coli strains isolated from children with community acquired urinary tract infections. African Journal of Microbiology Research 2011;5(26):4476-83.

22. Mendes JJ, Marques CA, Vilela C, Neves J, Candeias N, Cavaco-Silva P \& Melo-Cristino J. Clinical and bacteriological survey of diabetic foot infections in Lisbon. Diabetes Research and Clinical Practice 2012; 95(1):153-61.

23. Ramakant P, Verma AK, Misra R, Prasad KN, Chand G, Mishra $A$ et al. Changing microbiological profile of pathogenic bacteria in diabetic foot infections: time for a rethink on which empirical therapy to choose? Diabetologia $2011 ; 54(1): 58-64$.

24. Anvarinejad M, Pouladfar G, Bolandparvaz S, Satiary Z, Abbasi P \& Mardaneh J. Isolation and Antibiotic Susceptibility of the Microorganisms Isolated from Diabetic Foot Infections in Nemazee Hospital, Southern Iran. Journal of Pathogens 2015;7(1):101-10.

25. Oyibo SO, Jude E, Taraweh I, Nguyen H, Harkless LB \& Boulton AJM. A comparison of two Diabetic Foot ulcer classification systems: the Wagner and the University of Texas wound classification systems. Diabetes Care 2001;24(1):84-88.

26. Mendonca DA, Cosker T \& Makwan NK. Vacuum-assisted closure to aid wound healing in foot and ankle surgery. Foot Ankle Journal 2015;26(3):761-66.

27. Armstrong DG, Wrobel JS \& Robbins JM. Guest editorial: Are diabetes-related wounds and amputations worse than cancer? Wound J 2007;4(1):286-7.

28. Berendt AR, Peters EJ, Bakker K, Embil JM, Eneroth M, Hinchliffe RJ et al. Specific guidelines for treatment of diabetic foot osteomyelitis. Diabetes Metab Res Rev $2008 ; 24: 190$

29. Game FL \& Jeffcoate WJ Primarily non-surgical management of osteomyelitis of the foot in diabetes. Diabetologia 2008;51:962-7.

30. Ince P, Abbas ZG, Lutale JK, Basit A, Ali SM, Chohan F et al. Use of the SINBAD classification system and score in comparing outcome of foot ulcer management on three continents. Diabetes Care 2013;31:964-7.

31. Jeffcoate WJ \& Lipsky BA. Controversies in diagnosing and managing osteomyelitis in diabetes. Clin Infect Dis 2014;39:115-22. 